\title{
Gender Differences in Life Events Prior to Onset of Major Depressive Disorder: The Moderating Effect of Age
}

\author{
Kate L. Harkness and Nazanin Alavi \\ Queen's University \\ George M. Slavich \\ University of California, San Francisco
}

\author{
Scott M. Monroe \\ University of Notre Dame \\ Ian H. Gotlib \\ Stanford University
}

\author{
R. Michael Bagby \\ Centre for Addiction and Mental Health, University of Toronto
}

\begin{abstract}
Theoretical models attempting to explain why approximately twice as many women as men suffer from depression often involve the role of stressful life events. However, detailed empirical evidence regarding gender differences in rates of life events that precede onset of depression is lacking, due in part to the common use of checklist assessments of stress that have been shown to possess poor validity. The present study reports on a combined sample of 375 individuals drawn from 4 studies in which all participants were diagnosed with major depressive disorder and assessed with the Life Events and Difficulties Schedule (Bifulco et al., 1989), a state-of-the-art contextual interview and life stress rating system. Women reported significantly more severe and nonsevere, independent and dependent, and other-focused and subject-focused life events prior to onset of depression than did men. Further, these relations were significantly moderated by age, such that gender differences in rates of most types of events were found primarily in young adulthood. These results are discussed in term of their implications for understanding the etiological role of stressful life events in depression.
\end{abstract}

Keywords: stressful life events, major depression, gender differences, adolescence

One of the most consistent and enduring findings in research on major depressive disorder (MDD) is a higher prevalence of MDD in women than in men. This gender difference appears in early adolescence, reaches a rate of approximately $2: 1$ by midadolescence, and persists at least through the end of midlife (Hankin \& Abramson, 1999; Kessler, 2003). Gender differences in rates of MDD have been found cross culturally and cannot be accounted for by differences in treatment seeking (NolenHoeksema, 1993).

This article was published Online First September 20, 2010.

Kate L. Harkness and Nazanin Alavi, Department of Psychology, Queen's University, Kingston, Ontario, Canada; Scott M. Monroe, Department of Psychology, University of Notre Dame; George M. Slavich, Department of Psychiatry, University of California, San Francisco; Ian H. Gotlib, Department of Psychology, Stanford University; R. Michael Bagby, Department of Psychiatry, Centre for Addiction and Mental Health, University of Toronto, Toronto, Ontario, Canada.

This study was supported by a New Investigator award from the Sick Kids Foundation to Kate L. Harkness; an operating grant from the Ontario Mental Health Foundation to Kate L. Harkness and R. Michael Bagby; and National Institutes of Health Grant MH-60802 to Scott M. Monroe and Ian H. Gotlib.

Correspondence concerning this article should be addressed to Kate L. Harkness, Department of Psychology, Queen's University, Kingston, Ontario K7L 3N6, Canada. E-mail: harkness@queensu.ca
Several theoretical explanations have been proposed for the emergence and persistence of gender differences in rates of MDD, most of which implicate stressful life events in their explanatory framework (e.g., Cyranowski, Frank, Young, \& Shear, 2000; Hankin \& Abramson, 2001; Nolen-Hoeksema, 1993). In particular, these models postulate that women possess biological and psychological vulnerabilities (e.g., a ruminative response style, higher levels of the affiliative hormone oxytocin) that both increase rates of stressful life events and increase women's likelihood of developing MDD in the face of stressful life events. That is, a key tenet of these theoretical models is that stressful life events play a stronger role in the etiology of MDD in women than in men.

Our goal in the present paper is to examine fine-grained differences in the stressful life events that precede the onset of MDD to determine whether stressful life events may, indeed, be more strongly associated with the etiology of MDD in women than in men. Stressful life events clearly precede the onset of MDD in women. In a seminal series of studies conducted by George Brown and his colleagues in the United Kingdom, women with MDD were up to three times more likely to have experienced a major ("severe") life event in the 6 months prior to the onset of their depression than were nondepressed women in a comparable time period (Brown \& Harris, 1978, 1989). Further, using a large sample of female twin pairs, Kendler and colleagues documented a causal relation of life events to MDD and found that life events 
were the strongest proximal predictor of onset of MDD in women (Kendler, Gardner, \& Prescott, 2002; Kendler, Karkowski, \& Prescott, 1999).

Very little work has been done, however, to carefully characterize the relation of stressful life events to MDD in men. Further, it is as yet unclear whether depressed women are, indeed, more likely than depressed men to experience stressful life events prior to onset. Proper assessment of life events is crucial to addressing the etiological role of life events in MDD. In particular, a sophisticated measure of life stress is required that (a) firmly dates events with respect to MDD to ensure that events temporally precede onset; (b) provides detailed contextual information that permits ratings on dimensions of stress that are most relevant to etiology, such as severity; and (c) limits the influence of preexisting psychological vulnerabilities that may be confounded with gender and may bias the reporting of life events (e.g., ruminative response style; see Monroe \& Simons, 1991). Contextual life event interviews that employ anchored and objective rating systems, such as the Life Events and Difficulties Schedule (LEDS; Bifulco, Brown, $\&$ Harris, 1994), satisfy all three of these requirements (see Hammen, 2006; Monroe, 2008). However, this method is also time consuming and labor intensive. As a result, studies using the LEDS are often underpowered to examine fine-grained distinctions in terms of the life events that are likely to be most salient for MDD etiology.

Previous research has generally found no evidence for a gender difference in the overall number of life events occurring prior to onset of MDD (Hoffmann \& Su, 1998; Kendler, Thornton, \& Prescott, 2001; Maciejewski, Prigerson, \& Mazure, 2001; Perris, 1984; Williamson, Birmaher, Anderson, Al-Shabbout, \& Ryan, 1995; Zlotnick, Shea, Pilkonis, Elkin, \& Ryan, 1996). Further, longitudinal studies have found only limited support for the hypothesis that stressful life events predict the onset of MDD more strongly in women than in men (Maciejewski et al., 2001; Nazroo, Edwards, \& Brown, 1997; cf. Dalgard et al., 2006; Kendler, Kuhn, $\&$ Prescott, 2004; Kendler et al., 2001). Investigators have reported, however, that women may experience events that have particular relevance for the etiology of depression. In fact, this hypothesis has been explicitly integrated into theories of the gender differences in depression. For example, Cyranowski et al. (2000) posited that women's need for affiliation, mediated by hormonal changes at the pubertal transition, renders women particularly vulnerable to developing MDD in the face of interpersonal events. Consistent with this formulation, adult women report higher rates of life events involving their social network prior to the onset of MDD, whereas men report higher rates of events in the domains of work and crime (Dalgard et al., 2006; Kendler et al., 2001; Maciejewski et al., 2001). Again, the implication here is that the events that cluster in the period prior to MDD onset represent the stressors that were most central in triggering that onset.

There are two important limitations to the above research. First, previous studies have not examined the event dimensions that have been found in prior to research to have the most direct etiological relevance to MDD. This is important if one is examining a purported link between events and onset. Brown and Harris (1989) determined through their careful work using the LEDS that life events that occur in the 6 months prior to depression episode onset are the most central in precipitating that onset. Life events going further back in time than 6 months, in contrast, have substantially lower relevance to MDD onset. Further, severe events that are associated with at least a moderate degree of psychological threat are most strongly associated with MDD onset (e.g., job loss in a financially threatened context, spouse's unexpected request for separation after 20 years of marriage; Brown \& Harris, 1989; Kendler et al., 1999). Nonsevere events, although still unpleasant, may not have the psychological impact required to trigger an episode of MDD. Similarly, events that are at least in part dependent on the individual's own behavior (e.g., breakup of a romantic relationship) more strongly predict MDD onset than do independent life events (e.g., job loss due to factory closure; see, e.g., Kendler et al., 1999; Williamson et al., 1995; cf. Shrout et al., 1989). Further, whereas in general life events that are focused directly on the participant (i.e., involve mostly the participant; e.g., job loss) are more impactful than are events that occur to others (e.g., close friend's job loss; Brown \& Harris, 1989), research has determined that other-focused events are more common prior to MDD onset in women than in men (Dalgard et al., 2006; Kendler et al., 2001; Maciejewski et al., 2001). In the present study, examining gender differences in events occurring during the most etiologically central 6-month period prior to MDD onset stratified on these dimensions known to be most strongly associated with onset provided for a more complete understanding of the differential relation of stress to MDD in women versus men.

Second, previous studies examining gender differences in rates of stressful life events prior to MDD have not considered developmental changes in individuals' stressful life event context. Indirect evidence for the possibility that age might moderate gender differences in rates of life events prior to MDD comes from data suggesting that gender differences in life events may be more consistently supported in adolescent than in adult samples. Longitudinal studies of adolescents have found that negative life events predict MDD and general emotional maladjustment more strongly in girls than in boys (Bouma, Ormel, Verhulst, \& Oldehinkel, 2008; Ge, Lorenz, Conger, Elder, \& Simons, 1994; Rudolph \& Hammen, 1999; Shih, Eberhart, Hammen, \& Brennan, 2006; Silberg et al., 1999; Windle, 1992). It is important to note, though, that these were all community studies with low base rates of MDD, and most involved prediction of maladjustment (or symptoms) as opposed to the syndrome of MDD. Several also used self-report checklist measures of stress (for exceptions, see Rudolph \& Hammen, 1999; Shih et al., 2006) that may have been biased by factors that are known to be stronger in girls than in boys (e.g., rumination, negative cognitive style; Abela \& Hankin, 2008). Therefore, it is possible that findings in these studies may be driven by sex differences in these diathetic factors and not by differences in life events per se (see Monroe \& Simons, 1991). One study using the LEDS interview and examining overall rates of events in the 6-month period prior to the onset of MDD in adolescence found no evidence of gender differences (Williamson et al., 1995).

To our knowledge, there are no studies that have examined how gender differences in rates of stressful life events prior to MDD are moderated by age across adulthood. Previous research has determined that rates of life events decrease with age across adulthood, both in the general population (Henderson, Byrne, \& DuncanJones, 1981; Jordanova et al., 2007; Leskelä et al., 2004) and in individuals with MDD (Perris, 1984). Further, in a large epidemiological sample of 8,580 individuals ages $16-74$ from the United 
Kingdom, researchers found that the decline in life events with age was stronger in women than in men (Jordanova et al., 2007). However, these results do not speak to whether gender differences in the experience of stress prior to MDD onset are moderated by age. This latter question is key to understanding gender differences in the role of life stress in the etiology and pathology of MDD across the life course.

In the present article we provide a detailed examination of gender differences in life events prior to MDD onset assessed for an amalgamated sample of 375 individuals, recruited from four study sites, who were diagnosed with MDD. Our full sample is diverse in terms of sex, age (range $=13-65$ years), socioeconomic status, and geographic locale. Most important, life events for all individuals were assessed with the contextual LEDS system. As such, this sample allowed us to capitalize on the richness of the contextual method to address fine-grained questions that have previously been difficult to answer, given the necessity of a large sample. In particular, the present study was the first to examine gender and age differences in rates of life events experienced in the most etiologically central 6-month period prior to onset stratified on the basis of event dimensions that have the strongest relation to onset. Further, it is the first to examine whether age group moderates gender differences in rates of life events prior to MDD onset. In the present study we categorized our sample into four age groups that roughly map onto life span stages of development (Levinson, 1978): (a) adolescence (age 13-17); (b) young adulthood (age 18-29); (c) middle adulthood (age 30-49); and (d) upper middle adulthood (age 50-65). First, we predicted that women would report higher rates of (a) severe events, (b) dependent events, and (c) other-focused events than would men. Second, we predicted that rates of events prior to MDD onset would be higher in young adults than in adolescents and would decrease with age across middle and upper middle adulthood. Third, we predicted that age group would moderate gender differences in rates of events prior to onset. In particular, we predicted that gender differences in life events prior to MDD onset would emerge in the younger age groups (adolescence and young adulthood) but not in the older age groups.

\section{Method}

\section{Participants}

Participants were 375 individuals who met criteria for a current episode of MDD and who took part in one of four larger studies investigating the relation of stress to MDD. Participants from Study 1 were 52 adolescent boys and girls (ages 13-17) recruited with advertisements and from community mental health centers in a suburban city in southeastern Ontario, Canada (see Harkness, Bruce, \& Lumley, 2006). Participants in Study 2 were 76 adult women (ages 18-65) recruited with advertisements in a suburban city in Oregon (see Harkness \& Monroe, 2006). Participants in Study 3 were 100 adult men and women (ages 18-58) recruited with advertisements in the San Francisco Bay area (see Monroe, Slavich, Torres, \& Gotlib, 2007). Finally, participants in Study 4 were 147 adult men and women (ages 18-65) recruited via advertisements and doctor referrals in the Greater Toronto area (see Bulmash, Harkness, Stewart, \& Bagby, 2009). These prior reports give full details regarding recruitment.

All participants were required to meet criteria of the Diagnostic and Statistical Manual of Mental Disorders (DSM-IV; American Psychiatric Association, 1994) for a current episode of nonbipolar MDD with a duration of less than two years. The duration criterion was included to maximize recall of the events that occurred in the 6 months prior to episode onset (Brown \& Harris, 1978). Exclusion criteria consistent across all studies were the presence of a psychotic disorder, bipolar disorder, substance dependence, conduct disorder, or developmental disability (latter two diagnoses relevant to Study 1) and the presence of a medical disorder that could cause depression (by patient report; e.g., hypothyroidism). An additional inclusion criterion for Study 4 was a score of $\geq 16$ on the 17-item Hamilton Rating Scale for Depression (Hamilton, 1960). All participants had a minimum Grade 8 education and were fluent in reading English. Table 1 presents descriptive data separately for each study.

\section{Measures}

Diagnosis. Participants in Study 1 were administered all sections of the child and adolescent version of the Schedule for Affective Disorders and Schizophrenia (K-SADS; Kaufman, Birmaher, Brent, Rao, \& Ryan, 1996). Participants in Studies 2-4 were administered the Structured Clinical Interview for DSM-IV Axis I Disorders (SCID-I/P; First, Spitzer, Gibbon, \& Williams, 2002). The K-SADS and the SCID-I/P are semistructured clinical interviews that derive $D S M-I V$ Axis I diagnoses. Across studies, interviewers were advanced graduate students in clinical psychology who were trained to "gold standard" reliability status (see Grove, Andreasen, McDonald-Scott, Keller, \& Shapiro, 1981).

Depression severity. The 21-item self-report Beck Depression Inventory (BDI; Beck \& Steer, 1993) was administered to all participants to determine the presence and severity of depression symptoms. This measure is widely used in the study of depression

Table 1

Descriptive Characteristics by Study Site

\begin{tabular}{|c|c|c|c|c|c|}
\hline Variable & $\begin{array}{l}\text { Sex (male) } \\
n(\%)\end{array}$ & $\begin{array}{c}\text { Age } \\
M(S D)\end{array}$ & $\begin{array}{c}\text { Occupation (professional) } \\
n(\%)\end{array}$ & $\begin{array}{l}\text { BDI score } \\
M(S D)\end{array}$ & $\begin{array}{l}\text { Depression history } \\
\text { (first onset) } n(\%)\end{array}$ \\
\hline Study $1(n=52)$ & $15(29)_{\mathrm{a}}$ & $15.69(1.32)_{\mathrm{a}}$ & $23(44)_{a}$ & $24.02(11.68)_{\mathrm{a}}$ & $28(54)_{a}$ \\
\hline Study $2(n=76)$ & $0_{\mathrm{b}}$ & $37.30(11.12)_{\mathrm{b}}$ & $9(12)_{\mathrm{b}}$ & $28.61(8.51)_{b, c}$ & $9(12)_{\mathrm{b}}$ \\
\hline Study $3(n=100)$ & $26(26)_{a}$ & $35.10(10.40)_{\mathrm{b}}$ & $25(25)_{\mathrm{c}}$ & $25.81(8.17)_{\mathrm{a}, \mathrm{b}}$ & $18(18)_{\mathrm{b}}$ \\
\hline Study $4(n=147)$ & $48(33)_{a}$ & $38.32(13.54)_{\mathrm{b}}$ & $28(25)_{\mathrm{c}}$ & $30.52(7.90)_{\mathrm{c}}$ & $72(49)_{\mathrm{a}}$ \\
\hline
\end{tabular}

Note. Subscripts indicate group differences. $p<.05$. BDI $=$ Beck Depression Inventory; $S D=$ standard deviation. 
in adolescents and adults and has internal consistency estimates ranging from .73 to .95 (Beck, Steer, \& Garbin, 1988).

Stressful life events. The Life Events and Difficulties Schedule (LEDS-II; Bifulco et al., 1989) is a semistructured contextual interview and rating system that assesses recent stressful life events in 10 domains: education, occupation, housing, finances, role changes, legal, health, romantic relationships, other relationships, and deaths. The focus in the present study is on life events experienced in the 6-month period prior to the index MDD episode onset. All interviews were audiotaped. A research assistant then listened to the interviews and prepared vignettes of each event, deleting any information regarding the participant's depression and emotional reaction to the stressors. Rating teams at each site consisted of two to four raters who based their ratings on the LEDS manual, which includes explicit rules and criteria for rating life events, as well as over 5,000 case vignettes that are used to standardize the ratings. Raters had to justify each rating by appealing to specific vignettes. Studies have shown higher reliability and validity in the prediction of MDD with the LEDS than with checklist measures of stress (e.g., Brown \& Harris, 1989; McQuaid, Monroe, Roberts, Kupfer, \& Frank, 2000). Interrater reliability for event severity ratings averaged across the four studies reported here was $k=.90 .^{1}$

Life events were rated for "focus," which refers to the primary actor of the event, on a 3-point scale: 1 for subject (e.g., subject starts a job); 2 for joint (e.g., subject and boyfriend have a major argument); and 3 for other (e.g., subject's mother has a stroke). Subject- and joint-focused events were combined for analyses, as they predict vulnerability to MDD equally (Brown \& Harris, 1989). Life events were rated for their level of contextual threat (i.e., severity) on a 5-point scale $(1=$ marked, $2 \mathrm{a}=$ high moderate, $2 \mathrm{~b}=$ low moderate, $3=$ some, $4=$ little/none). Each rater provided his or her own threat rating for each event. Discrepancies among raters were discussed, and a consensus threat rating was achieved. This consensus rating was used in all analyses. Severe events were rated 1 (marked) or $2 \mathrm{a}$ (high moderate) on threat and 1 (subject) or 2 (joint) on focus (e.g., a woman learns that her husband of 10 years, on whom she is financially dependent, is having an affair). Nonsevere events were rated $2 \mathrm{~b}$ (low moderate), 3 (some), or 4 (little/none) on threat and could be of any focus (e.g., participant has an argument with a close friend that is resolved within a week).

Events were also rated for independence. Independent life events were judged as totally or nearly totally independent of the actions or behavior of the individual (e.g., job loss due to plant closure, grandmother's death from cancer). Dependent life events were judged as at least partly dependent on the participant's actions or behavior (e.g., quit job, filed for divorce). Consensus decisions regarding independence were based on the context surrounding each event and adhered to the rules for making such distinctions found in the LEDS manual.

Event variables used in analyses were defined as event totals, except in the case of severe events and other-focused events. Because latter types of life events were too infrequent to permit parametric analyses, they were dichotomized as presence versus absence. Thus, the event variables used in analyses included the total number of subject/joint-focused events, the presence versus absence of an other-focused event, the total number of nonsevere events, the presence versus absence of a severe event, the total number of dependent events, and the total number of independent events. All events were reported for the most etiologically central 6-month time period prior to onset of the index episode (Brown \& Harris, 1978).

\section{Procedure}

Ethical approval for each study was obtained by each institution's research ethics board. All participants and a parent or guardian for those under 18 provided written informed consent. Full details regarding each study procedure are provided in previous reports. Briefly, in Study 1, adolescents participated in two 2-hr assessments separated by one week. The K-SADS and questionnaires were administered during Session 1, and the LEDS was administered during Session 2. In Study 2, women participated in one 3-hr assessment. Again, the SCID-I/P interview and questionnaires were administered before the LEDS interview. In Study 3 , participants took part in three interview sessions, each separated by approximately one week. The SCID-I/P was administered during Session 1, and the LEDS was administered in Session 3.

Study 4 was a treatment trial. Participants completed the SCID and questionnaires prior to beginning the trial. Participants were then randomized to receive 16 weeks of cognitive-behavioral therapy, interpersonal psychotherapy, or antidepressant medication according to a standard treatment algorithm. At the completion of the trial, participants were administered the LEDS interview, which covered the period from 6 months prior to onset of the index episode through the treatment trial (see Bulmash et al., 2009).

\section{Data Analysis}

We tested the hypotheses with a series of 2 (sex: female vs. male) $\times 4$ (age group) analyses of variance (ANOVAs) using SPSS statistical software. The general linear model, which utilizes Type III sums of squares to account for unequal cell sizes, was employed. Estimated marginal means are reported in all figures. Four age groups were constructed that roughly correspond to life span stages of development: (a) adolescence (ages 13-17; $n=34$ girls, 14 boys), (b) young adulthood (ages 18-29; $n=95$ women, 19 men), (c) middle adulthood (ages $30-49 ; n=123$ women, 32 men), and (d) upper middle adulthood (ages 50-65; $n=34$ women, 24 men). We chose not to examine age as a continuous variable, because we were not hypothesizing a linear relation of age and life events and because developmental discontinuities across age do not necessarily follow a linear trajectory. The dependent variables for the ANOVAs included the total number of (a) events regardless of focus, severity, or independence; (b) subject/joint-focused events; (c) dependent events; (d) independent

\footnotetext{
${ }^{1}$ Kate L. Harkness supervised the LEDS ratings in Studies 1, 2, and 4, and Scott M. Monroe supervised the LEDS ratings in Studies 1 and 3. In addition, the rating teams overlapped across Studies 1 and 4 . The LEDS addresses the issue of rater drift by relying on anchoring of life event ratings to the manual. Prior to making a rating, each member of the rating team must appeal to an example in the LEDS manual upon which he or she is basing the rating. This feature enhances the validity and intersite reliability of the LEDS and ensures that all ratings are made according to the same criteria.
} 
events; and (e) nonsevere events, respectively. Skew for all variables was within acceptable limits $(<|2|)$.

Other-focused and severe events were dichotomized (present/ absent) as noted above, due to low frequencies, and were tested in logistic regression models. The main effects of gender and age group were entered in the first step, and the interaction was entered in the second step.

\section{Results}

\section{Site Differences and Descriptive Characteristics}

Excluding Study 2, which included only women, sex was not differentially distributed across the study sites, $\chi^{2}(2)=1.29, p=$ .53 (see Table 1). Excluding Study 1, which included only adolescents, age did not differ significantly across studies, $F(2,320)=$ 2.12, $p=.12$. Occupation status differed across studies, $\chi^{2}(3)=$ $17.35, p<.005$, with Study 1 reporting the highest occupation status (in this case, of the parents). Study 1 and Study 4 had the highest proportion of individuals in their first episode of depression, $\chi^{2}(3)=51.96, p<.001$. Study 4 and Study 2 had significantly higher BDI scores than did Study $1, F(3,371)=9.95, p<$ .001 .

Table 2 presents the descriptive characteristics of the full sample of 375 participants stratified by our two variables of interest: sex and age group. In the full sample, male and female participants did not differ significantly in terms of age or BDI scores. However, male participants were significantly more likely than female participants to be employed (or have their parents employed) in a professional occupation, $\chi^{2}(3)=7.73, p<.005$, and to be experiencing their first onset of depression, $\chi^{2}(1)=5.16, p<.05$. In terms of age group, the 13- to 17-year-olds and the 50- to 70-yearolds had a higher proportion of males than did the other groups, $\chi^{2}(3)=14.72, p<.005$. Further, the 13 - to 17 -year-olds had a significantly higher (parental) occupation status, $\chi^{2}(3)=11.66$, $p<.005$, lower BDI scores, $F(3,371)=4.40, p<.01$, and $\mathrm{a}$ higher percentage of individuals on a first onset of depression, $\chi^{2}(3)=24.46, p<.005$, than did the three adult groups.

Results of models that included depression history (first onset vs. recurrence), socioeconomic status, and depression severity (BDI scores) did not differ from those of uncontrolled models. Further, in exploratory analyses we failed to find evidence for twoor three-way interactions of depression history and either sex ( $p$ s $\left.>.64, \eta^{2}<.001\right)$ or age group $\left(p s>.30, \eta^{2}<.003\right)$. Therefore, we present the uncontrolled models below for ease of interpretability. ${ }^{2}$

\section{Gender Differences in Life Events Prior to Onset of MDD}

Descriptive statistics of life events stratified by sex and by age group are presented in Table 3. As generally predicted, the ANOVA model examining total number of events overall revealed a significant main effect of age group, $F(3,367)=3.22, p<.05$, $\eta^{2}=.026$, as well as a significant interaction of sex and age group, $F(3,367)=3.52, p<.05, \eta^{2}=.03$. The homogeneity of variance assumption was not upheld for this analysis, $F(7,367)=4.55, p<$ .005. Therefore, we performed bootstrapping procedures on the interaction to establish the robustness of this effect (Howell, 2007).
Sampling 5,000 times from our distribution resulted in a significant mean bootstrapped $F$ of $4.23(p=.01){ }^{3}$

Simple effects contrasts conducted on the interaction revealed that female participants experienced significantly more events than did male participants, $F(1,367)=13.74, p<.001, \eta^{2}=.04$, but only among those in the 18- to 29-year-old age group (see Figure 1). Further, among female participants, the 18- to 29-year-olds reported significantly more life events than did those in the $50+$ age group, $F(1,367)=18.60, p<.001, \eta^{2}=.05$. The pattern was reversed for male participants, with 18- to 29-year-olds reporting fewer life events than did the 13- to 17-year-olds, $F(1,367)=$ 4.63, $p<.05, \eta^{2}=.012$.

Event focus. The analysis of subject/joint-focused events yielded a significant main effect of age group, $F(1,367)=3.57$, $p<.05, \eta^{2}=.03$, and a significant Sex $\times$ Age Group interaction, $F(3,367)=2.98, p<.05, \eta^{2}=.024$. Again, the homogeneity of variance assumption was not upheld for this analysis, $F(7,367)=$ $6.13, p<.005$. Bootstrapping procedures on the interaction that sampled 5,000 times from our distribution resulted in a mean bootstrapped $F$ of $3.65(p=.02)$.

As displayed in Figure 2a, female participants reported significantly more subject/joint-focused events than did male participants, $F(1,367)=11.30, p<.005, \eta^{2}=.03$, but only among those in the 18- to 29-year-old age group. Further, for female participants, 18- to 29-year-olds reported significantly more subject/joint-focused events than did the 13- to 17-year-olds, $F(1$, $367)=5.61, p<.05, \eta^{2}=.02$, and those in the 50+ age group, $F(1,367)=22.26, p<.001, \eta^{2}=.06$. Again, this pattern was reversed (although not statistically significantly so) in male participants.

The first step of the logistic regression model examining the relation of sex and age group to the presence versus absence of an other-focused event was significant, $\chi^{2}(4)=14.20, p<.01$, as was the model including the interaction of sex and age group, $\chi^{2}(7)=20.45, p<.005$ (see Figure 2b). The nature of the interaction differed significantly between the $50+$ group and the other three age groups, odds ratio $(O R)=5.18$, Wald $=5.20, \mathrm{CI}_{95}$ [1.26, 21.27]. In particular, female participants were more likely to have an other-focused event prior to onset than were male participants in all age groups except those over 50.

Event independence. For dependent events, there was a significant main effect of age group, $F(3,367)=4.03, p<.01, \eta^{2}=$ .03 , which was moderated by sex at a trend level, $F(3,367)=$ 2.12, $p<.10, \eta^{2}=.02$. Again, the homogeneity of variance

\footnotetext{
${ }^{2}$ To increase our power to detect interactions with depression history, we also ran separate models testing only the two-way interactions of sex and depression history (both controlling for and not controlling for age group) and of age group and depression history (both controlling for and not controlling for sex). Again, none of these two-way interactions emerged as significant ( $p s>.47$, all $\eta^{2}<.008$ ). Further, we collapsed age group into the two categories of most relevance to the episode number distinction: adolescents (13-18) versus adults (19+). Again, none of the two-way or three-way interactions of depression history with sex and/or the dichotomous age group emerged as significant $\left(p s>.24\right.$, all $\left.\eta^{2}<.005\right)$. Results of the analyses including episode number, socioeconomic status, and depression severity are available from the authors by request.

${ }^{3}$ The parametric critical value for $F(3,367)$ is 2.61 , with the probability of $F$ less than 1 (null hypothesis value).
} 
Table 2

Descriptive Statistics of Demographic and Clinical Variables Stratified by Sex and Age

\begin{tabular}{|c|c|c|c|c|c|}
\hline Variable & $\begin{array}{c}\text { Sex (male) } \\
n(\%)\end{array}$ & $\begin{array}{c}\text { Age } \\
M(S D)\end{array}$ & $\begin{array}{c}\text { Occupation (professional) } \\
n(\%)\end{array}$ & $\begin{array}{l}\text { BDI score } \\
M(S D)\end{array}$ & $\begin{array}{l}\text { Depression history } \\
\text { (first onset) } n(\%)\end{array}$ \\
\hline \multicolumn{6}{|l|}{ Sex } \\
\hline Male $(n=89)$ & & 35.65 (14.99) & $29(37)_{\mathrm{a}}$ & $26.93(8.80)$ & $39(44)_{a}$ \\
\hline Female $(n=286)$ & & $33.63(12.97)$ & $56(21)_{b}$ & $28.30(9.08)$ & $88(31)_{b}$ \\
\hline \multicolumn{6}{|l|}{ Age group } \\
\hline $13-17(n=48)$ & $14(29)_{\mathrm{a}, \mathrm{d}}$ & & $21(44)_{\mathrm{a}}$ & $23.71(11.87)_{\mathrm{a}}$ & $27(56)_{\mathrm{a}}$ \\
\hline $18-29(n=114)$ & $19(17)_{\mathrm{b}}$ & & $15(19)_{\mathrm{b}}^{\mathrm{a}}$ & $28.60(8.52)_{\mathrm{b}}$ & $49(43)_{\mathrm{b}}^{\mathrm{a}}$ \\
\hline $30-49(n=155)$ & $32(21)_{\mathrm{a}}$ & & $34(22)_{\mathrm{b}}$ & $28.33(8.45)_{\mathrm{b}}$ & $36(23)_{\mathrm{c}}$ \\
\hline $50-70(n=58)$ & $24(41)_{\mathrm{c}, \mathrm{d}}$ & & $15(26)_{\mathrm{b}}$ & $29.33(7.84)_{\mathrm{b}}$ & $15(26)_{\mathrm{c}}$ \\
\hline
\end{tabular}

Note. Age is in years. Subscripts indicate group differences. $p<.05$. BDI $=$ Beck Depression Inventory; $S D=$ standard deviation.

assumption was not upheld for this analysis, $F(7,367)=5.13, p<$ .005. Bootstrapping on the interaction sampling 5,000 times from our distribution confirmed the results of the general linear model, resulting in a mean bootstrapped $F$ of $2.77(p=.08)$. The pattern of means is presented in Figure 3a.

For independent events, there was a significant main effect of sex, $F(1,367)=4.90, p<.05, \eta^{2}=.013$, and the age group effect approached significance, $F(1,367)=2.38, p<.10, \eta^{2}=.02$. The interaction of sex and age also approached significance, $F(1$, $367)=2.45, p<.10, \eta^{2}=.02$. Bootstrapping on the interaction sampling 5,000 times from our distribution confirmed the results of the general linear model, resulting in a mean bootstrapped $F$ of $3.04(p=.07)$. Of note, and in contrast to the above pattern for dependent events, female participants did not differ significantly in their rates of independent events across the four age groups, $F(3$, $282)=1.05, p=.37$. The pattern of means is presented in Figure $3 b$.

Event severity. For nonsevere events, there was a significant main effect of age, $F(3,367)=5.59, p<.005, \eta^{2}=.04$, which was significantly moderated by sex, $F(3,367)=3.95, p<.01$, $\eta^{2}=.03$. The homogeneity of variance assumption was not upheld for this analysis, $F(7,367)=7.99, p<.005$. Bootstrapping procedures on the interaction with 5,000 iterations resulted in a significant mean bootstrapped $F$ of $4.80(p=.003)$.

The pattern of this interaction is displayed in Figure $4 \mathrm{a}$, such that female participants reported significantly more nonsevere events than did male participants, $F(1,367)=14.67, p<.001$, $\eta^{2}=.04$, in the 18 -to 29 -year-old group only. In addition, the 18 - to 29-year-old women reported significantly more nonsevere events than did women in the $50+$ age group, $F(1,367)=21.80$ $p<.001, \eta^{2}=.06$. In contrast, the 18 - to 29-year-old men reported significantly fewer nonsevere events than did the male adolescents, $F(1,367)=6.94, p<.01, \eta^{2}=.02$.

For severe events, as predicted, the logistic regression model containing the interaction of sex and age group was significant, $\chi^{2}(7)=14.69, p<.05$, such that the nature of the gender difference between the adolescent and the adult groups differed significantly, $O R=5.99$, Wald $=4.23, p<.05, \mathrm{CI}_{95}[1.09,33.33]$ (see Figure 4b). Adolescent girls and boys did not differ significantly in their likelihood of a severe event. Among the adults, women were significantly more likely than men to have had a severe event prior to onset across all three age groups.

\section{Discussion}

In the present study, we provided a detailed examination of gender differences in life events using a rigorous contextual life event interview with a relatively large and well-diagnosed sample. Overall totals of life events as well as more specific categories of life events that have etiological relevance to MDD were examined. Further, this is the first study to consider gender differences in life events prior to MDD onset in the context of adolescent and adult development. Consistent with predictions, clear evidence was found for a female preponderance in rates of life events prior to MDD onset. Further, the gender difference for most life events was significant in early adulthood (age 18-29) but failed to reach

Table 3

Descriptive Statistics of Event Variables Stratified by Sex and Age

\begin{tabular}{|c|c|c|c|c|c|c|c|}
\hline Variable & $\begin{array}{l}\text { Total overall } \\
M(S D)\end{array}$ & $\begin{array}{l}\text { Subject-focused } \\
M(S D)\end{array}$ & $\begin{array}{c}\text { Other-focused } \\
n(\%)\end{array}$ & $\begin{array}{l}\text { Nonsevere } \\
M(S D)\end{array}$ & $\begin{array}{l}\text { Severe } \\
n(\%)\end{array}$ & $\begin{array}{c}\text { Dependent } \\
M(S D)\end{array}$ & $\begin{array}{c}\text { Independent } \\
M(S D)\end{array}$ \\
\hline \multicolumn{8}{|l|}{ Sex } \\
\hline Male $(n=89)$ & $1.93(1.93)_{\mathrm{a}}$ & $1.60(1.79)_{\mathrm{a}}$ & $19(21)$ & $1.46(1.63)_{\mathrm{a}}$ & $11(12)_{\mathrm{a}}$ & $1.42(1.60)_{\mathrm{a}}$ & $0.53(0.95)_{\mathrm{a}}$ \\
\hline Female $(n=286)$ & $2.83(2.71)_{\mathrm{b}}$ & $2.36(2.48)_{\mathrm{b}}$ & $88(31)$ & $2.06(2.23)_{\mathrm{b}}$ & $73(25)_{\mathrm{b}}$ & $1.97(2.30)_{\mathrm{b}}$ & $0.86(1.14)_{\mathrm{b}}$ \\
\hline \multicolumn{8}{|l|}{ Age group } \\
\hline $13-17(n=48)$ & $3.04(2.30)_{\mathrm{a}, \mathrm{b}}$ & 2.35 (1.99) & $22(46)_{a}$ & $2.60(1.98)_{\mathrm{a}}$ & $11(23)$ & $2.00(1.74)$ & $1.04(1.06)$ \\
\hline $18-29(n=114)$ & $3.40(3.16)_{\mathrm{b}}$ & $2.96(2.96)_{\mathrm{a}}$ & $36(32)_{\mathrm{b}}$ & $2.61(2.64)_{\mathrm{a}}$ & $29(25)$ & $2.59(2.75)_{a}$ & $0.82(1.09)$ \\
\hline $30-49(n=155)$ & $2.25(2.15)_{\mathrm{a}, \mathrm{c}}$ & $1.92(2.00)_{\mathrm{b}}$ & $34(22)_{\mathrm{b}}$ & $1.50(1.59)_{\mathrm{b}}$ & $31(20)$ & $1.57(1.82)_{\mathrm{b}}$ & $0.68(1.02)$ \\
\hline $50-70(n=58)$ & $1.72(2.23)_{\mathrm{c}}$ & $1.17(1.58)_{\mathrm{b}}$ & $15(26)_{\mathrm{b}}$ & $1.14(1.73)_{\mathrm{b}}$ & $13(22)$ & $0.95(1.37)_{\mathrm{b}}$ & $0.78(1.36)$ \\
\hline
\end{tabular}

Note. Age is in years. Subscripts indicate group differences. $S D=$ standard deviation. $p<.05$. 


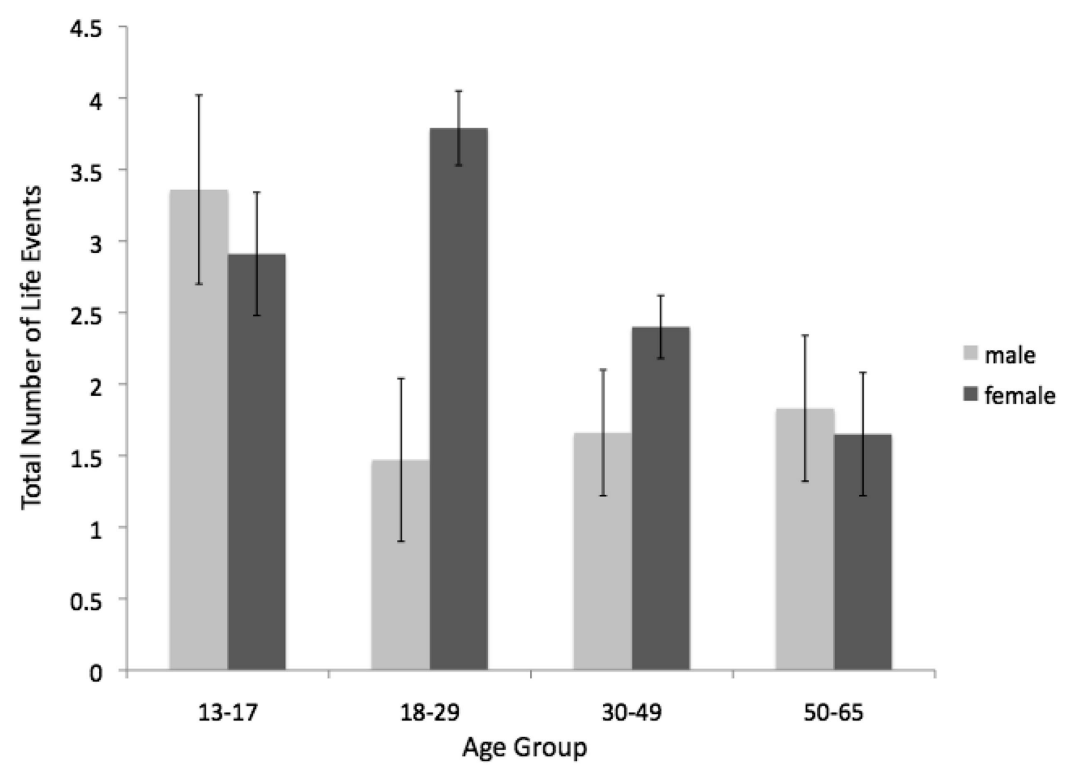

Figure 1. Total number of life events reported in 6 months prior to onset by sex and age.

significance in the mid-adult and upper middle adult groups. The present results are inconsistent with the previous literature, which has failed to find gender differences in rates of pre-onset life events. This discrepancy may be accounted for by the inclusion in these previous studies of a relatively older adult sample. Consistent with studies using the LEDS in adolescence, however, gender differences were not detected in our adolescent age group for any life event variable except other-focused events. Our results suggest, therefore, that the gender difference in rates of stressful life events prior to MDD onset is most pronounced in young adulthood.

\section{Gender Differences in Life Events in Adulthood}

Depressed women were significantly more likely to report a severe life event prior to MDD onset than were men across all three adult groups. Because it is severe events that are most strongly associated with the onset of MDD episodes, this finding may have significant implications for understanding the differential relation of stress to the etiology of MDD in women versus men (Brown \& Harris, 1989; Hammen, 2006). It is important to note that our design is cross-sectional. Nevertheless, because these events occurred in close temporal proximity to MDD onset for women, this result suggests that severe stress may play a more prominent role in the etiology of MDD in women than in men.

It is unclear why rates of severe life events prior to MDD onset in men were so low. One possibility may be that men simply do not perceive these events as stressful and thus minimize their significance during the interview. This is unlikely to account for the present results, however, because the LEDS does not assess respondents' perceptions of stressfulness. It is the indication of event occurrence and relevant factual details that the raters use to objectively determine the event's contextual threat with reference to standardized case vignettes. Furthermore, severe events are high impact and unlikely to be forgotten over the short time period of the study. Alternatively, men may be preferentially sensitized to stress and, thus, could be more likely to succumb to depression in the face of nonsevere events than of severe events (Monroe \& Harkness, 2005). This explanation is also unlikely, however, because greater sensitivity to life events should translate into higher rates of nonsevere events prior to onset in men, which was not the case in our sample.

A further potential explanation for our results may be that life stress is not as central to the etiology of MDD for men, as other factors (e.g., history of depression, biological or genetic dispositions) play a greater role. Consistent with this suggestion, Kendler, Gardner, and Prescott (2006) have reported that stressful life events in their sample of close to 3,000 male twin pairs have a weaker direct relation to depression onset in men versus women, with genetic risks, childhood loss, and low self-esteem having stronger and broader impacts in men.

Consistent with predictions, depressed women in all age groups except those over 50 were significantly more likely than were depressed men to report other-focused events prior to onset. Consistent with Cyranowski et al. (2000), it is possible that women are more sensitive to life events occurring to others (and thus would see these events clustered in close proximity to onset) due to their greater tendency to affiliate (e.g., Buss \& Barnes, 1986) and to take on caregiving roles (Neal, Ingersoll-Dayton, \& Starrels, 1997). Of note, only two of the $19(10.5 \%)$ young adult men and only four of the $32(12.5 \%)$ 30-to 45-year-old men reported an other-focused life event prior to onset of depression. Future prospective studies that predict the onset of MDD from other-focused events differentially in women versus men are necessary to clarify the exact processes mediating this gender difference.

The very high rates of life events prior to onset in the young adult women raise the possibility that these women may be in part creating their stressful environment (Hammen, 1991; Kendler \& Karkowski-Shuman, 1997). Although the present study was not designed to test hypotheses related to stress generation, it is compelling that women experienced similar rates of independent 
(a) Subject-Focused Events

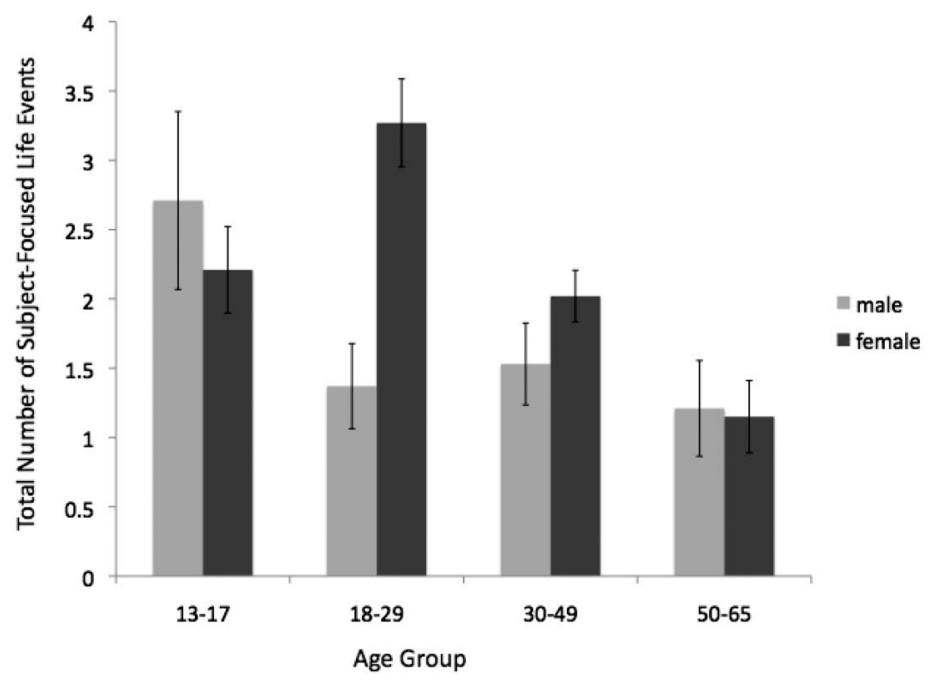

(b) Other-Focused Events

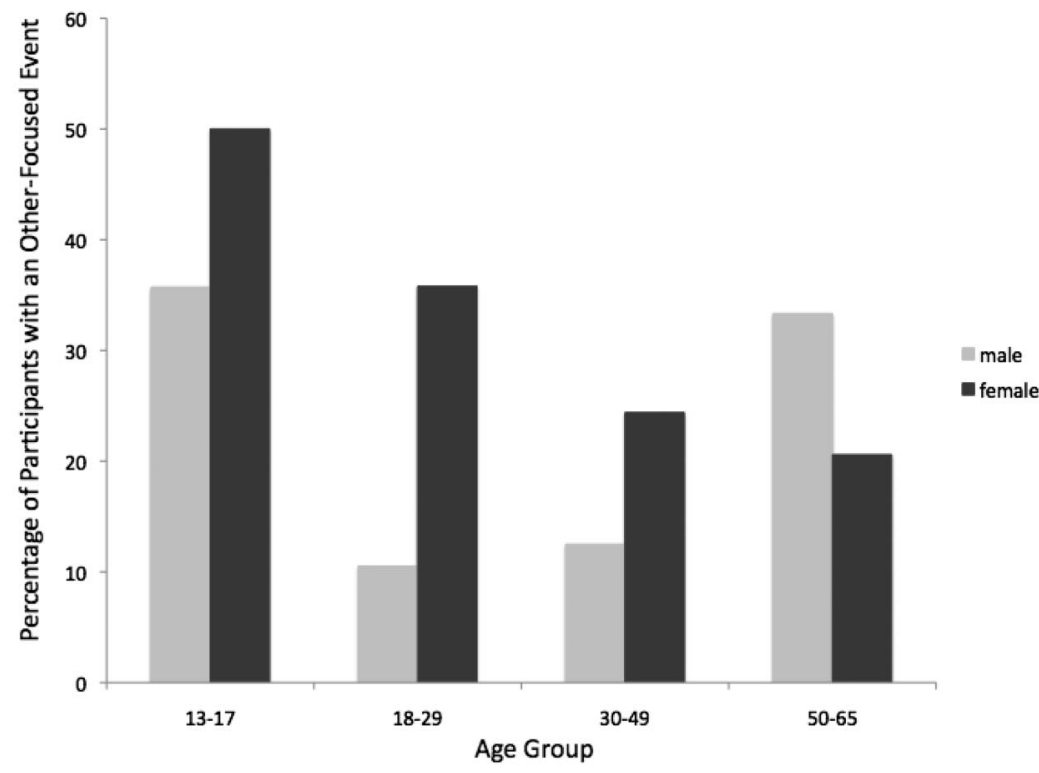

Figure 2. Differences by sex and age in (a) subject-focused and (b) other-focused life events in 6 months prior to onset.

events across age, but rates of dependent events were much higher in the young adulthood groups than the older adult groups (see Figures $3 \mathrm{a}-\mathrm{b}$ ). Indeed, the transition to young adulthood has been identified as a period of stress generation for women (e.g., Daley, Hammen, \& Rao, 2000). A descriptive look at the life event profiles of some of these young women supports this assertion. For example, in just the 6 months prior to MDD onset, one woman started and then subsequently was fired from two different jobs, was served an eviction notice, and experienced the loss of two confiding relationships. Another young woman was caught in an extramarital affair after which her partner left her, was served an eviction notice, and fell out with her two best friends. These descriptions and those from other women in this age group point to turmoil in a number of domains that is at least in part caused by the women themselves. Future research is required to understand how the generation of life events plays a role in gender differences in the etiological relation of stress to MDD.

\section{Gender Differences in Life Events in Adolescence}

We generally failed to find evidence in adolescents for gender differences in rates of life events prior to MDD onset. Adolescents were more likely than those in the other age groups to be in a first episode of depression, raising the possibility that our results can be better accounted for by depression history. This is unlikely, however, because all of our models were robust when controlling for 
(a) Dependent events

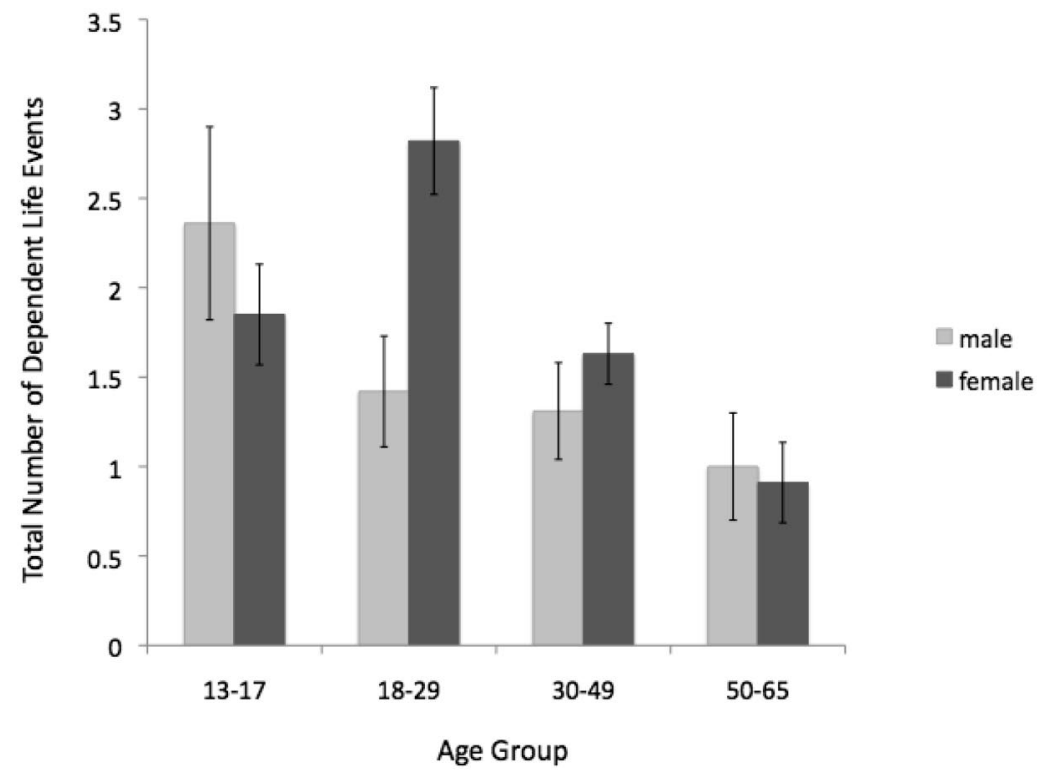

(b) Independent events

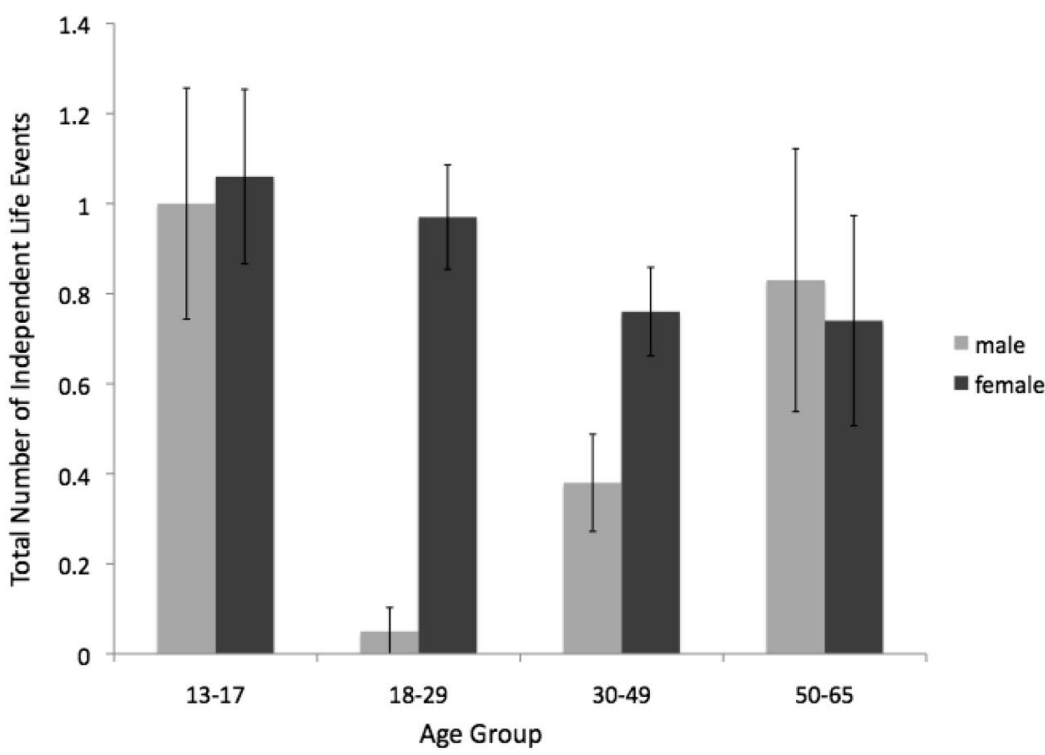

Figure 3. Differences by sex and age in (a) dependent and (b) independent life events in 6 months prior to onset.

depression history. Further, we failed to find evidence for two-way interactions of depression history and either sex or age group (see Footnote 2). Therefore, individual differences across sex and age group in the frequency of life events prior to MDD onset was independent of differences due to the progression of the depression syndrome. Nevertheless, the potential role of depression history in further understanding gender differences in life events prior to MDD should be examined in future research with much larger samples.

Of particular note, adolescent boys and girls did not differ significantly in the percentage experiencing a severe event prior to onset, suggesting that stress may play a similar role in the etiology of depression in these initial onsets of depression during adolescence. A very important question for future research, then, is to understand what changes between adolescence and young adulthood that accounts for the significant increase in frequency of life events prior to onset in women and the significant decrease in life events prior to onset in men. As noted above, previous research has focused on young women's transition to adulthood and has documented high rates of stress generation in this group as a way of understanding the explosion of new cases of depression at this time. However, the present results suggest that it may be equally 
(a) Non-severe events

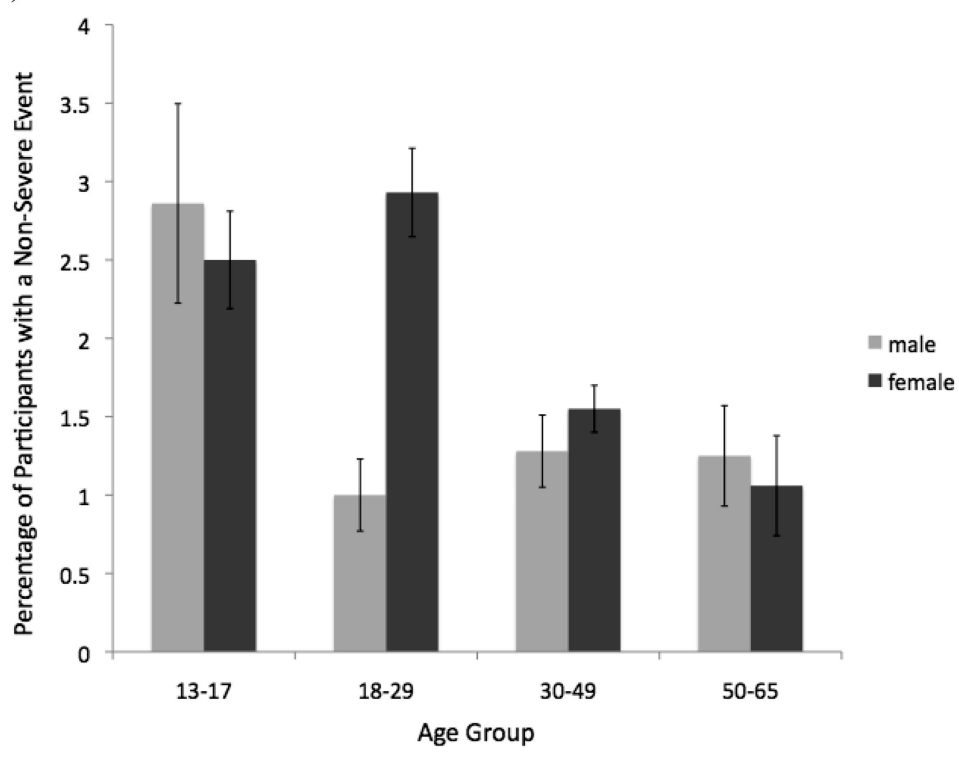

(b) Severe events

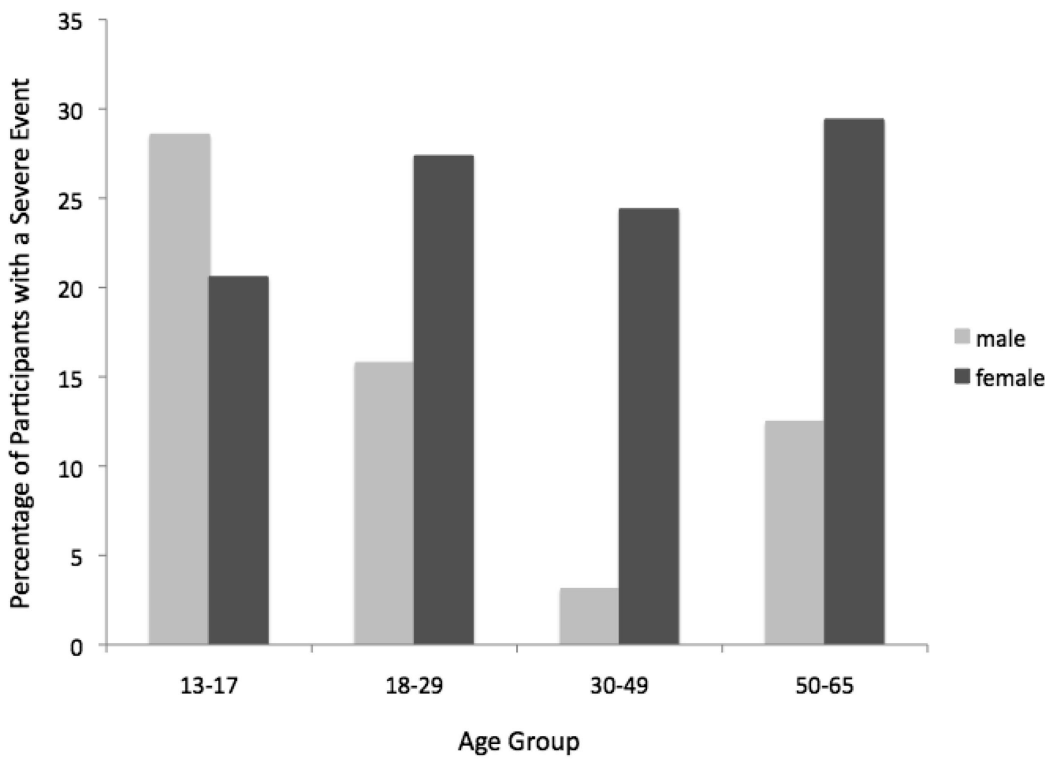

Figure 4. Differences by sex and age in (a) nonsevere and (b) severe life events in 6 months prior to onset.

important to study changes in the etiological relation of events to onset during the transition to young adulthood in women and in men to fully understand the mechanism through which life events cause depression.

As expected, adolescents reported lower rates of most life events than did adults. Nevertheless, adolescents had the highest rates of other-focused and independent events, many of which were events that had happened to the adolescents' parents (e.g., father loses job, mother has a bout of pneumonia). The ratio of independent to dependent events in the adolescents was also higher (54\%) than in the adults (only $29 \%$ for the young adults). Indeed, this lack of control over the environment just as adolescents are individuating may help to explain the potency of independent events in the onset of MDD in adolescence (Harkness et al., 2006).

\section{Limitations}

The present results should be interpreted in light of the following limitations. First, despite our large sample for this type of research, we were limited in the number of men in the present analyses. Men made up only about a quarter of the sample overall (89/275), and numbers of men were particularly small in the young adult group $(n=19 / 114 ; 17 \%)$ and mid-adult group $(n=32 / 155$; $21 \%$ ). In the present study this was likely due to the inclusion of 
a sample drawn from a study that included only women (Study 2). The small number of men limits the generalizability of our findings, and future research that oversamples for depressed men is required to confirm the results reported here. Nevertheless, it is important to note that the standard errors of the life event variables in these two cells with relatively smaller numbers were not notably larger than those observed in the remaining cells (see Figures 1-4). Further, we performed a number of measures to ensure the robustness of our findings, including bootstrapping analyses on all of our interaction terms.

Second, our sample did not include children (age $<13$ ) or the old (age $>70$ ). These are particularly important groups to examine because there is evidence that the gender difference in rates of MDD may not be as prominent in these groups as it is in adolescents and non-old adults (Bebbington et al., 1998; Bland, Newman, \& Orn, 1988; Kessler, McGonagle, Swartz, Blazer, \& Nelson, 1993). Third, our sample was constrained for looking at moderators (e.g., socioeconomic status, depression history, comorbidity). All results were robust when controlling for these variables, which suggests that our pattern was not confounded, for example, by an overrepresentation of first-onset, lower severity, and higher SES cases in the younger age groups. Nevertheless, future studies are required to more specifically examine the role of these factors in understanding the mechanism through which life events trigger MDD. Finally, because life event information was collected retrospectively, biases on the part of participants may have influenced the report of event occurrence and severity. The LEDS addresses the issue of respondent bias by employing rigorously trained raters who apply standardized rules and criteria when conducting rating of the events. Raters were also blind to the date of onset of MDD for respondents and to their subjective perceptions of the events (see McQuaid et al., 2000).

In summary, gender differences in life events prior to onset emerged for almost every type of event studied. It is particularly noteworthy, in adults, that depressed women maintained higher rates of severe life events throughout adulthood than did depressed men. This finding suggests that stress may play a different role in the triggering of episodes of depression for men and women and that other dimensions of life stress, as well as non-stress-related factors, may figure more prominently in the etiology of depression for men. Our results indicate a similar level of environmental disruption in adolescent boys and girls with MDD. These results have important clinical implications. Treatment interventions that emphasize stress coping may be effective in promoting remission and preventing relapse for boys and for girls in adolescence. However, in adulthood, such interventions may be useful only in the treatment of depression in women. The precision of definition in our measurement of life stress and our focus on life events that most reliably predict onsets of MDD sets this study apart from many previous studies of gender differences in stress. The present findings help us to gain a better understanding of individual differences in the etiological role of life stress over the lifetime course of depression.

\section{References}

Abela, J. R. Z., \& Hankin, B. L. (2008). Cognitive vulnerability to depression in children and adolescents: A developmental psychopathology perspective. In J. R. Z. Abela \& B. L. Hankin (Eds.), Handbook of child and adolescent depression (pp. 35-78). New York, NY: Guilford Press.

American Psychiatric Association. (1994). Diagnostic and statistical manual of mental disorders (4th ed.). Washington, DC: Author.

Bebbington, P. E., Dunn, G., Jenkins, R., Lewis, G., Brugha, T., Farrell, M., \& Meltzer, H. (1998). The influence of age and sex on the prevalence of depressive conditions: Report from the National Survey of Psychiatric Morbidity. Psychological Medicine, 28, 9-19. doi:10.1017/ S0033291797006077

Beck, A. T., \& Steer, R. A. (1993). Manual for the Beck Depression Inventory-II. San Antonio, TX: Psychological Corporation.

Beck, A. T., Steer, R. A., \& Garbin, M. G. (1988). Psychometric properties of the Beck Depression Inventory: Twenty-five years of evaluation. Clinical Psychology Review, 8, 77-100. doi:10.1016/02727358(88)90050-5

Bifulco, A., Brown, G., Edwards, A., Harris, T., Neilson, E., Richards, C., \& Robinson, R. (1989). Life Events and Difficulties Schedule (LEDS-2): Vol. 1. Life events manual. London, England: Royal Holloway and Bedford New College, University of London.

Bifulco, A., Brown, G. W., \& Harris, T. O. (1994). Childhood Experience of Care and Abuse (CECA): A retrospective interview measure. Journal of Child Psychology and Psychiatry, 35, 1419-1435.

Bland, R. C., Newman, S. C., \& Orn, H. (1988). Period prevalence of psychiatric disorders in Edmonton. Acta Psychiatrica Scandinavica, 77(Suppl. 338), 33-42. doi:10.1111/j.1600-0447.1988.tb08545.x

Bouma, E. M., Ormel, J., Verhulst, F. C., \& Oldehinkel, A. J. (2008). Stressful life events and depressive problems in early adolescent boys and girls: The influence of parental depression, temperament and family environment. Journal of Affective Disorders, 105, 185-193. doi: 10.1016/j.jad.2007.05.007

Brown, G. W., \& Harris, T. O. (1978). Social origins of depression. London, England: Tavistock.

Brown, G. W., \& Harris, T. O. (1989). Life events and illness. New York, NY. Guilford Press.

Bulmash, E., Harkness, K. L., Stewart, J. G., \& Bagby, R. M. (2009). Personality, stressful life events, and treatment response in major depression. Journal of Consulting and Clinical Psychology, 77, 10671077. doi:10.1037/a0017149

Buss, D. M., \& Barnes, M. (1986). Preferences in human mate selection. Journal of Personality and Social Psychology, 50, 559-570. doi: 10.1037/0022-3514.50.3.559

Cyranowski, J. M., Frank, E., Young, E., \& Shear, M. K. (2000). Adolescent onset of the sex difference in lifetime rates of major depression. Archives of General Psychiatry, 57, 21-27. doi:10.1001/archpsyc .57 .1 .21

Daley, S. E., Hammen, C., \& Rao, U. (2000). Predictors of first onset and recurrence of major depression in young women during the 5 years following high school graduation. Journal of Abnormal Psychology, 109, 525-533. doi:10.1037/0021-843X.109.3.525

Dalgard, O. S., Dowrick, C., Lehtinen, V., Vazquez-Barquero, J. L., Casey, P., Wilkinson, G., ... Dunn, G. (2006). Negative life events, social support and sex difference in depression: A multinational community survey with data from the ODIN study. Social Psychiatry and Psychiatric Epidemiology, 41, 444-451. doi:10.1007/s00127-006-0051-5

First, M. B., Spitzer, R. L., Gibbon, M., \& Williams, J. B. W. (2002). Structured Clinical Interview for DSM-IV-TR Axis I Disorders, Research Version, Patient Edition. (SCID-I/P). New York, NY: Biometrics Research.

Ge, X., Lorenz, F. O., Conger, R. D., Elder, G. H., \& Simons, R. L. (1994). Trajectories of stressful life events and depressive symptoms during adolescence. Developmental Psychology, 30, 467-483. doi:10.1037/ 0012-1649.30.4.467

Grove, W. M., Andreasen, N. C., McDonald-Scott, P., Keller, M. B., \& 
Shapiro, R. W. (1981). Reliability studies of psychiatric diagnosis: Theory and practice. Archives of General Psychiatry, 38, 408-413.

Hamilton, M. A. (1960). A rating scale for depression. Journal of Neurology, Neurosurgery \& Psychiatry, 23, 56-62. doi:10.1136/jnnp.23.1.56

Hammen, C. (1991). Generation of stress in the course of unipolar depression. Journal of Abnormal Psychology, 100, 555-561. doi:10.1037/ 0021-843X.100.4.555

Hammen, C. (2006). Stress generation in depression: Reflections on origins, research, and future directions. Journal of Clinical Psychology, 62, 1065-1082. doi:10.1002/jclp.20293

Hankin, B. L., \& Abramson, L. Y. (1999). Development of sex differences in depression: Description and possible explanations. Annals of Medicine, 31, 372-379. doi:10.3109/07853899908998794

Hankin, B. L., \& Abramson, L. Y. (2001). Development of sex differences in depression: An elaborated cognitive vulnerability-transactional stress theory. Psychological Bulletin, 127, 773-796. doi:10.1037/00332909.127.6.773

Harkness, K. L., Bruce, A. E., \& Lumley, M. N. (2006). The role of childhood abuse and neglect in the sensitization to stressful life events in adolescent depression. Journal of Abnormal Psychology, 115, 730-741. doi:10.1037/0021-843X.115.4.730

Harkness, K. L., \& Monroe, S. M. (2006). Severe melancholic depression is more vulnerable than non-melancholic depression to minor precipitating life events. Journal of Affective Disorders, 91, 257-263. doi: 10.1016/j.jad.2005.12.009

Henderson, A. S., Byrne, D. G., \& Duncan-Jones, P. (1981). Neurosis and the social environment. Sydney, Australia: Academic Press.

Hoffmann, J. P., \& Su, S. S. (1998). Stressful life events and adolescent substance use and depression: Conditional and sex differentiated effects. Substance Use and Misuse, 33, 2219-2262. doi:10.3109/ 10826089809056256

Howell, D. C. (2007). Fundamental statistics for the behavioral sciences (6th ed.). Belmont, CA: Thomson Wadsworth.

Jordanova, V., Stewart, R., Goldberg, D., Bebbington, P. E., Brugha, T., Singleton, N., ... Meltzer, H. (2007). Age variation in life events and their relationship with common mental disorders in a national survey population. Social Psychiatry and Psychiatric Epidemiology, 42, 611616. doi:10.1007/s00127-007-0209-9

Kaufman, J., Birmaher, B., Brent, D., Rao, U., \& Ryan, N. (1996). Kiddie-SADS-Present and Lifetime Version (K-SADS-PL). Pittsburgh, PA: University of Pittsburgh Medical School.

Kendler, K. S., Gardner, C. O., \& Prescott, C. A. (2002). Toward a comprehensive developmental model for major depression in women. American Journal of Psychiatry, 159, 1133-1145. doi:10.1176/ appi.ajp.159.7.1133

Kendler, K. S., Gardner, C. O., \& Prescott, C. A. (2006). Toward a comprehensive developmental model for major depression in men. American Journal of Psychiatry, 163, 115-124. doi:10.1176/ appi.ajp.163.1.115

Kendler, K. S., Karkowski, L. M., \& Prescott, C. A. (1999). The causal relationship between stressful life events and the onset of major depression. American Journal of Psychiatry, 156, 837-841.

Kendler, K. S., \& Karkowski-Shuman, L. M. (1997). Stressful life events and genetic liability to major depression: Genetic control of exposure to the environment. Psychological Medicine, 27, 539-547. doi:10.1017/ S0033291797004716

Kendler, K. S., Kuhn, J., \& Prescott, C. A. (2004). The interrelationship of neuroticism, sex, and stressful life events in the prediction of episodes of major depression. American Journal of Psychiatry, 161, 631-636. doi: 10.1176/appi.ajp.161.4.631

Kendler, K. S., Thornton, L. M., \& Prescott, C. A. (2001). Sex differences in the rates of exposure to stressful life events and sensitivity to their depressogenic effects. American Journal of Psychiatry, 158, 587-593. doi:10.1176/appi.ajp.158.4.587
Kessler, R. C. (2003). Epidemiology of women and depression. Journal of Affective Disorders, 74, 5-13. doi:10.1016/S0165-0327(02)00426-3

Kessler, R. C., McGonagle, K. A., Swartz, M., Blazer, D. G., \& Nelson, C. B. (1993). Sex and depression in the National Comorbidity Survey I: Lifetime prevalence, chronicity and recurrence. Journal of Affective Disorders, 29, 85-96. doi:10.1016/0165-0327(93)90026-G

Leskelä, U. S., Melartin, T. K., Lestelä-Mielonen, P. S., Rytsälä, H. J., Sokero, T. P., Heikkinen, M. E., \& Isometsä, E. T. (2004). Life events, social support, and onset of major depressive episode in Finnish patients. Journal of Nervous and Mental Disease, 192, 373-381. doi:10.1097/ 01.nmd.0000126705.15497.c9

Levinson, D. J. (1978).The seasons of a man's life. New York, NY: Knopf. Maciejewski, P. K., Prigerson, H. G., \& Mazure, C. M. (2001). Sex differences in event-related risk for major depression. Psychological Medicine, 31, 593-604. doi:10.1017/S0033291701003877

McQuaid, J. R., Monroe, S. M., Roberts, J. E., Kupfer, D. J., \& Frank, E. (2000). Comparison of two life stress assessment approaches: Prospective prediction of treatment outcome in recurrent depression. Journal of Abnormal Psychology, 109, 787-791. doi:10.1037/0021-843X.109.4.787

Monroe, S. M. (2008). Modern approaches to conceptualizing and measuring human life stress. Annual Review of Clinical Psychology, 4, 33-52. doi:10.1146/annurev.clinpsy.4.022007.141207

Monroe, S. M., \& Harkness, K. L. (2005). Life stress, the "kindling" hypothesis, and the recurrence of depression: Considerations from a life stress perspective. Psychological Review, 112, 417-445. doi:10.1037/ 0033-295X.112.2.417

Monroe, S. M., \& Simons, A. D. (1991). Diathesis-stress theories in the context of life stress research: Implications for the depressive disorders. Psychological Bulletin, 110, 406-425. doi:10.1037/0033-2909.110.3.406

Monroe, S. M., Slavich, G. M., Torres, L. D., \& Gotlib, I. H. (2007). Severe life events predict specific patterns of change in cognitive biases in major depression. Psychological Medicine, 37, 863-871. doi: 10.1017/S0033291707000281

Nazroo, J. Y., Edwards, A. C., \& Brown, G. W. (1997). Sex differences in the onset of depression following a shared life event: A study of couples. Psychological Medicine, 27, 9-19. doi:10.1017/S0033291796004187

Neal, M. B., Ingersoll-Dayton, B., \& Starrels, M. E. (1997). Sex and relationship differences in caregiving patterns and consequences among employed caregivers. Gerontologist, 37, 804-816.

Nolen-Hoeksema, S. (1993). Sex differences in depression. Stanford, CA: Stanford University Press.

Perris, H. (1984). Life events and depression: Part 1. Effect of sex, age, and civil status. Journal of Affective Disorders, 7, 11-24. doi:10.1016/01650327(84)90060-0

Rudolph, K. D., \& Hammen, C. (1999). Age and sex as determinants of stress exposure, generation, and reactions in youngsters: A transactional perspective. Child Development, 70, 660-677. doi:10.1111/14678624.00048

Shih, J. H., Eberhart, N. K., Hammen, C. L., \& Brennan, P. A. (2006). Differential exposure and reactivity to interpersonal stress predict sex differences in adolescent depression. Journal of Clinical Child and Adolescent Psychology, 35, 103-115. doi:10.1207/s15374424jccp3501_9

Shrout, P. E., Link, B. G., Dohrenwend, B. P., Skodol, A. E., Stueve, A., \& Mirotznik, J. (1989). Characterizing life events as risk factors for depression: The role of fateful loss events. Journal of Abnormal Psychology, 98, 460-467. doi:10.1037/0021-843X.98.4.460

Silberg, J., Pickles, A., Rutter, M., Hewitt, J., Simonoff, E., Maes, H., . . Eaves, L. (1999). The influence of genetic factors and life stress on depression among adolescent girls. Archives of General Psychiatry, 56, 225-232. doi:10.1001/archpsyc.56.3.225

Williamson, D. E., Birmaher, B., Anderson, B. P., Al-Shabbout, M., \& Ryan, N. D. (1995). Stressful life events in depressed adolescents: The role of dependent events during the depressive episode. Journal of the 
American Academy of Child \& Adolescent Psychiatry, 34, 591-598. doi:10.1097/00004583-199505000-00011

Windle, M. (1992). A longitudinal study of stress buffering for adolescent problem behaviors. Developmental Psychology, 28, 522-530. doi: 10.1037/0012-1649.28.3.522

Zlotnick, C., Shea, M. T., Pilkonis, P. A., Elkin, I., \& Ryan, C. (1996). Sex, type of treatment, dysfunctional attitudes, social support, life events, and depressive symptoms over naturalistic follow-up. American Journal of Psychiatry, 153, 1021-1027.

Received September 17, 2009

Revision received May 12, 2010

Accepted May 18, 2010

\section{Call for Nominations}

The Publications and Communications (P\&C) Board of the American Psychological Association has opened nominations for the editorships of Journal of Experimental Psychology: Learning, Memory, and Cognition; Professional Psychology: Research and Practice; Psychology and Aging; Psychology, Public Policy, and Law; and School Psychology Quarterly for the years 2013-2018. Randi C. Martin, PhD, Michael C. Roberts, PhD, Ronald Roesch, PhD, and Randy W. Kamphaus, $\mathrm{PhD}$, respectively, are the incumbent editors.

Candidates should be members of APA and should be available to start receiving manuscripts in early 2012 to prepare for issues published in 2013. Please note that the P\&C Board encourages participation by members of underrepresented groups in the publication process and would particularly welcome such nominees. Self-nominations are also encouraged.

Search chairs have been appointed as follows:

- Journal of Experimental Psychology: Learning, Memory, and Cognition, Leah Light, $\mathrm{PhD}$, and Valerie Reyna, PhD

- Professional Psychology: Research and Practice, Bob Frank, PhD, and Lillian Comas-Diaz, $\mathrm{PhD}$

- Psychology and Aging, Leah Light, PhD

- Psychology, Public Policy, and Law, Peter Ornstein, PhD, and Brad Hesse, PhD

- School Psychology Quarterly, Neal Schmitt, PhD, and Jennifer Crocker, PhD

Candidates should be nominated by accessing APA's EditorQuest site on the Web. Using your Web browser, go to http://editorquest.apa.org. On the Home menu on the left, find "Guests." Next, click on the link "Submit a Nomination," enter your nominee's information, and click "Submit."

Prepared statements of one page or less in support of a nominee can also be submitted by e-mail to Sarah Wiederkehr, P\&C Board Search Liaison, at swiederkehr@apa.org.

Deadline for accepting nominations is January 10, 2011, when reviews will begin. 